\title{
Field Testing of a Pneumatic Regolith Feed System During a 2010 ISRU Field Campaign on Mauna Kea, Hawaii
}

\author{
Jack Craft $^{1}$, Kris Zacny ${ }^{2}$, Philip Chu $^{3}$, Jack Wilson ${ }^{4}$, Chris Santoro ${ }^{5}$, Lee Carlson ${ }^{6}$, and Michael Maksymuk. ${ }^{7}$ \\ Honeybee Robotics, New York, NY 10001 \\ Ivan I. Townsend ${ }^{8}$ \\ Arctic Slope Regional Corporation (ASRC) Aerospace, Kennedy Space Center, FL \\ and \\ Robert P. Mueller ${ }^{9}$, James G.Mantovani ${ }^{10}$ \\ National Aeronautics \& Space Administration (NASA), Kennedy Space Center, FL
}

\begin{abstract}
Lunar In Situ Resource Utilization (ISRU) consists of a number of tasks starting with mining of lunar regolith, followed by the transfer of regolith to an oxygen extraction reactor and finally processing the regolith and storing of extracted oxygen. The transfer of regolith from the regolith hopper at the ground level to an oxygen extraction reactor many feet above the surface could be accomplished in different ways, including using a mechanical auger, bucket ladder system or a pneumatic system. The latter system is commonly used on earth when moving granular materials since it offers high reliability and simplicity of operation. In this paper, we describe a pneumatic regolith feed system, delivering feedstock to a Carbothermal reactor and lessons learned from deploying the system during the 2010 ISRU field campaign on the Mauna Kea, Hawaii.
\end{abstract}

\section{Introduction}

In-Situ Resource Utilization (ISRU) refers to mining and processing of local resources, such as regolith or waterice found on extra-terrestrial bodies in support of human and to some extent also robotic surface operations ${ }^{1,2,3,4}$. The major premise for ISRU is cost reduction associated with not having to haul supplies and consumables to an extraterrestrial body, but instead producing them in-situ. For example the historical cost of placing $1 \mathrm{~kg}$ on the surface of the Moon is of the order of $\$ 50,000$ to $\$ 100,000$. Thus, a processing plant weighing for example $10 \mathrm{~kg}$ and delivering $100 \mathrm{~kg}$ of consumables over its life, will save $90 \mathrm{~kg}$ in mass and up to $\$ 9 \mathrm{M}$ in cost. Lunar ISRU is also being considered as an enabling technology for human and robotic exploration of Mars and beyond. In particular, oxygen produced from lunar regolith could be used as an oxidizer for the propulsion systems and sent to a refueling station in earth orbit or to the Lagrange points. Mars bound spacecrafts could thus re-fuel before proceeding to the red planet. With launch costs to LEO at $\sim \$ 10-20 \mathrm{~K} / \mathrm{kg}$ this approach could also offer substantial savings.

ISRU consists of a number of steps that include 1) mining of a resource (e.g. regolith), 2) moving it to a processing plant, 3) pre-processing the resource (e.g. crushing, sieving or pre-heating), 4) moving the feedstock

\footnotetext{
${ }^{1}$ Project Manager, Honeybee Robotics, 460 West $34^{\text {th }}$ Street, New York, NY 10001

${ }^{2}$ Senior Research Scientist, Honeybee Robotics, 460 West $34^{\text {th }}$ Street, New York, NY 10001

${ }^{3}$ Systems Engineer, Honeybee Robotics, 460 West $34^{\text {th }}$ Street, New York, NY 10001

${ }^{4}$ Systems Engineer, Honeybee Robotics, 460 West $34^{\text {th }}$ Street, New York, NY 10001

${ }^{5}$ Project Engineer, Honeybee Robotics, 460 West $34^{\text {th }}$ Street, New York, NY 10001

${ }^{6}$ Project Engineer, Honey bee Robotics, 460 West $34^{\text {th }}$ Street, New York, NY 10001

${ }^{7}$ Systems Engineer, Honeybee Robotics, 460 West $34^{\text {th }}$ Street, New York, NY 10001

${ }^{8}$ Mechanical Engineer, Advanced Systems, ASRC Aerospace, ASRC-48, Kennedy Space Center, FL 32899

${ }^{9}$ Chief of the Surface Systems Office, NE-S, Kennedy Space Center, FL 32899

${ }^{10}$ Physicist, Surface Systems Office, NE-S-1, Kennedy Space Center, FL 32899.
} 
from the pre-processing plant or a hopper to a ISRU reactor, 5) extraction of the valuable resource (e.g. water and oxygen in an ISRU reactor (e.g. Carbothermal or Hydrogen Reduction system), 6) disposal of the waste product.

In this paper we focus on step 4, which is the delivering of highly abrasive lunar soil feedstock directly into an ISRU oxygen extraction reactor. Since moving the regolith is in the critical path of the entire ISRU system, reliability is of paramount importance. The system operation has to address the extreme lunar environment (vacuum, low and high temperatures), the unique properties of the feedstock (highly abrasive regolith) and robotic operation.

Many systems for lifting lunar regolith have been proposed before. These include, for example, conventional augers or bucket ladder systems. However, these are mechanical systems and thus prone to failures, especially when conveying highly abrasive regolith. An alternative system is to use pneumatic conveying, which is commonly used on earth to convey granular material. This system has stood the test of time $e^{5}$. Recent results from tests conveying JSC-1a lunar soil simulant in vacuum and at lunar gravity during parabolic flights have shown that pneumatic systems are both a very efficient ${ }^{6,7}$ and also very effective ${ }^{8}$ method for moving small or large quantities of regolith. In particular, we found that with just 1 gram of gas at 5 psia we could efficiently loft $6000 \mathrm{~g}$ of JSC-1a at high velocity $(>10 \mathrm{~m} / \mathrm{s})$. The gas is not necessarily a consumable - the entire system in fact could be a closed loop system and the gas could be recycled. The initial mass of gas can be supplied from the ullage of propulsion systems. The helium pressurant normally vented after touch down could be tapped into and unspent fuel could be burned in a small rocket thruster and exhaust gasses delivered to a gas tank. An additional source of gas could come from the ISRU reactor itself, which produces many gaseous by-products.

In this paper we describe the pneumatic feed system and lessons learned from demonstrating this technology as part of the 2010 ISRU field test campaign at Mauna Kea. The system fed regolith to a Carbothermal reactor (manufactured by Orbitec, inc) using recycled air. The vertical distance from a lower collection hopper to the Carbothermal reactor's intake hopper was approximately 1.6 meters. The benefit of the system was having very few moving parts. In an extraterrestrial setting, such as the Moon or Mars, this would minimize the wear caused to moving parts by abrasive soil particles. The relative simplicity of the system provides comparatively few opportunities for malfunction.

The project requirements were to:

1. Successfully demonstrate the elements of a closed-loop pneumatic transfer system in an analog environment.

2. Successfully integrate the system with the Orbitec Carbothermal reactor. This included receiving commands from the Carbothermal reactor's control system and delivering tephra to the Carbothermal reactor hopper.

3. Successfully accept tephra delivery from an excavation rover.

\section{Hardware Design and Assembly}

\section{A. Requirements of the Pneumatic Feed System}

The principal requirement for the pneumatic regolith feed system was to lift tephra from a hopper at ground level to the Carbothermal reactor's input hopper at a height of approximately 1.6 meters. Allowances also had to be made for field conditions, including uneven ground. The success objective was to accomplish this using air as a recycled working fluid, and the success threshold was to accomplish this using compressed gas as a consumable.

\section{B. System Description}

The general layout of the pneumatic feed system's major components is illustrated in Figure 1. Gas travels around a loop while transporting regolith, which enters the airflow at the eductor, and is separated from the airflow at the cyclone separators. Additional components and control measures support these essential components. A compressor provides the pressure necessary to maintain the airflow, and is sized to provide the pressure and volumetric flowrate consistent with the design point of the eductor. Valves are used to control the flow of air and regolith. A hopper stores the regolith as it awaits transport, and a funnel directs the regolith upon exit. A HEPA filter protects the compressor from undue wear by capturing any fine particles that make it past the cyclones.

The system as implemented is illustrated in Figure 2. Regulators control the pressure that the compressor delivers to the system, and pressure relief valves prevent the pressure from reaching or undesirable levels. A small line is added to divert a fraction of the airflow into the hopper, which serves to stir and fluidize the regolith inside, preventing bridging and encouraging flow. If the hopper lid is sealed, this make-up air also prevents the formation of a vacuum as the regolith empties into the main flow.

The system's Programmable Logic Controller (PLC) may be programmed to turn the compressor on and off and to open and close the two valves. Alternatively, the valves and compressor may be switched at the manual control box. The valves may also be opened or closed by turning the valve handles by hand. 
The manual control box is also the location of the main power switch and the emergency stop. The main power switch has provisions for safety lockout. The manual control box features a mechanical interlock to prevent opening the box unless the main power switch is off.

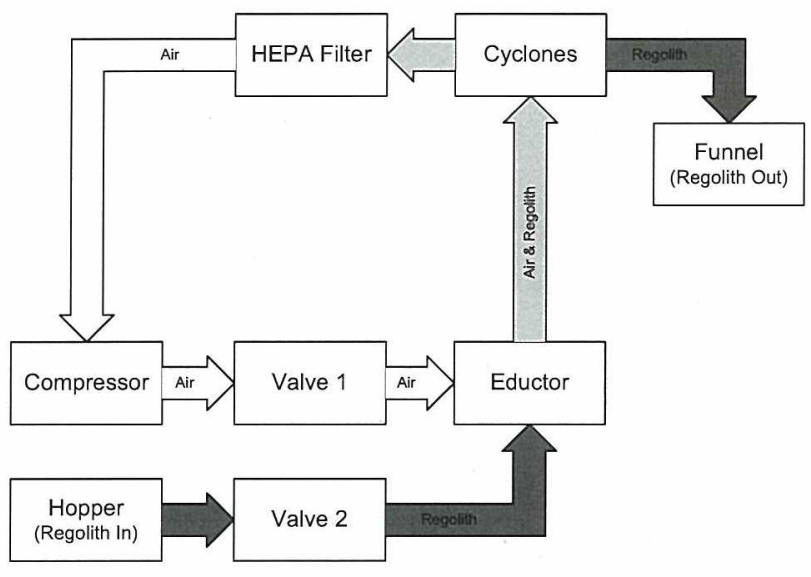

Figure 1. Simplified Schematic of the Pneumatic Regolith Feed System. Airflow (light gray and white arrows) is kept within a closed loop. Regolith enters the airflow at the eductor, and exits the airflow at the cyclones. The HEPA filter captures any fine particles that make it past the cyclones.

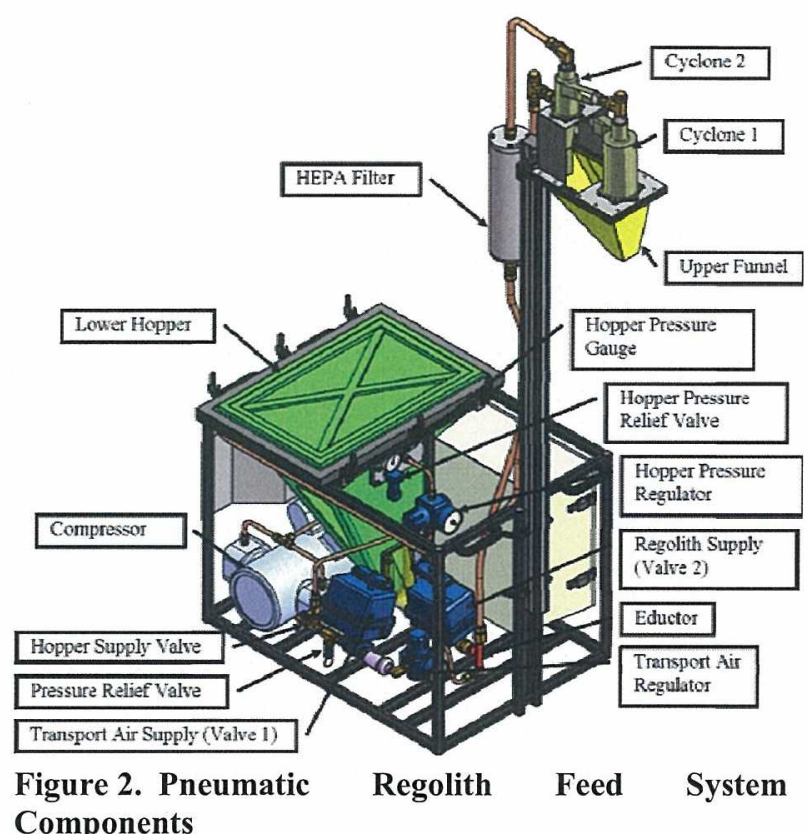

\section{Location and Tephra Feedstock}

The field demonstration was conducted on the slopes of Mauna Kea, an inactive volcano on the island of Hawai'i. Soil at the demonstration site consists largely of tephra - fragmental material produced by volcanic eruption. For the pneumatic regolith feed system, we are specifically interested in tephra particles smaller than $2 \mathrm{~mm}$ in diameter, or volcanic ash (Figure 3). Particles greater than $2 \mathrm{~mm}$ in diameter could clog the system by lodging in the eductor. The field team had all tephra sieved before being deposited in the hopper to prevent clogging due to oversized particles. The tephra of Mauna Kea is culturally significant, and may not be permanently removed. The tephra borrowed for this effort was treated with due care and returned after use.
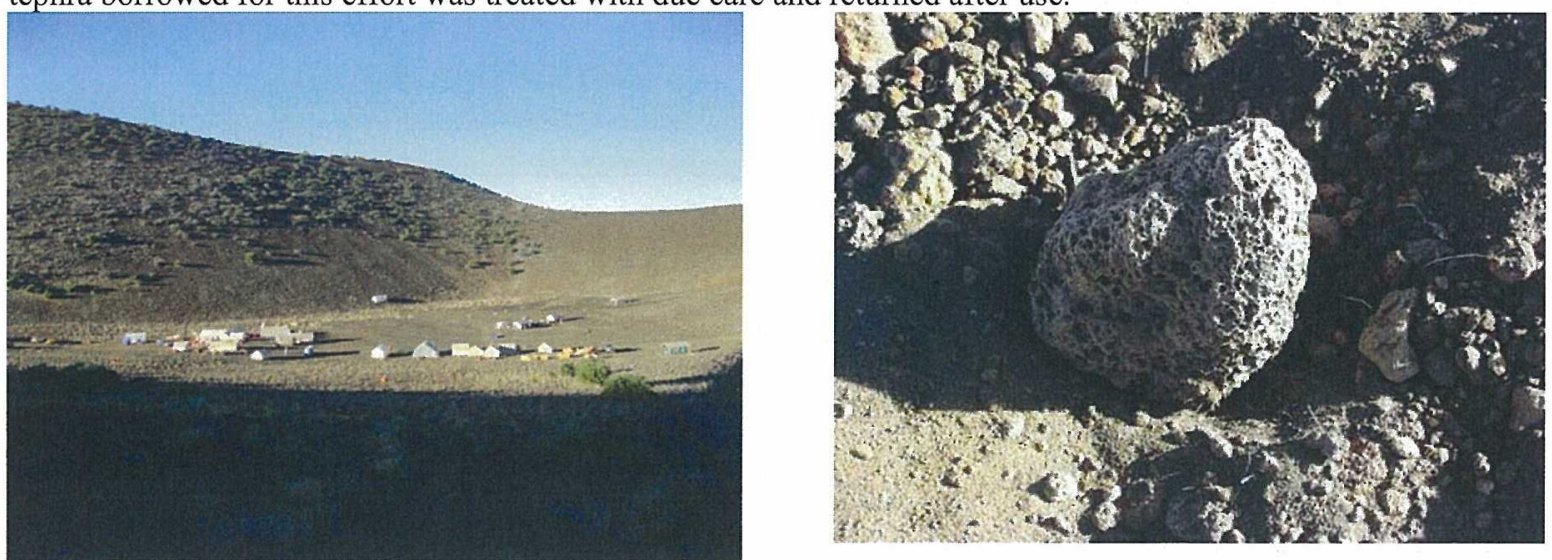

Figure 3. Left: View of the Camp on the slopes of Mauna Kea, HI. Right: Mauna Kea tephra: particles larger than $2 \mathrm{~mm}$ were excluded to avoid clogging the eductor. 


\section{Dust Mitigation}

Initial tests demonstrated that fine particles may be lofted airborne during tephra transfer. The generation of dust is a consequence of the non-contact interface with the Carbothermal Reactor. The non-contact interface is not sealed, and provides an opportunity for fine particles to generate a dust cloud as they fall into the Carbothermal Reactor's hopper.

During acceptance testing, NASA/KSC requested that Honeybee take measures to mitigate the dust generation so that the system could be confidently operated in the field without causing inconvenience or harm to surrounding personnel and equipment. In order to mitigate the dust generated, Honeybee sealed potential leak paths around the cyclones and output funnel, and introduced a "dust sock" to prevent the tephra fines from being lofted as they exit the output funnel (Figure 4). This relatively minor modification nevertheless had an impact on the rate at which the system delivered tephra.

\section{Test Results}

\section{A. Tephra Transfer Rate}

The rate at which the pneumatic feed system transfers tephra was determined by periodically weighing the amount of tephra delivered into a receptacle. In cases where the tephra was delivered to the Carbothermal Reactor's input hopper, the Orbitec team provided a mass estimate based on the amount of time it took for the Carbothermal Reactor to ingest the tephra using its auger. See the appendix for graphs of the test results.

\section{Validation and Acceptance Testing}

Validation and acceptance testing was performed at Honeybee's Brooklyn facility and was witnessed by NASA/KSC personnel. Approximately $35 \mathrm{~kg}$ of tephra was transferred during acceptance testing. The average rate of transfer during these tests was 0.63 $\mathrm{kg}$ /minute, or approximately $5 \mathrm{~kg}$ every 8 minutes (Figure 7 and Figure 8).

\section{Post-Dust Mitigation Testing}

Approximately $10 \mathrm{~kg}$ of tephra was transferred to verify functionality and quantify any change in performance after dust mitigation measures were added. The average rate of transfer during these tests was $0.54 \mathrm{~kg} /$ minute, or approximately $5 \mathrm{~kg}$ every 9.5 minutes (Figure 9). This is a $14 \%$ decrease in rate of transfer relative to the validation and acceptance testing.

3. Field Testing

Approximately $35 \mathrm{~kg}$ of tephra was transferred during the field test (Figure 10). The average rate of transfer during these tests was $0.52 \mathrm{~kg} /$ minute, or approximately $5 \mathrm{~kg}$ every 10 minutes. The rate of transfer ranged from a minimum value of $0.37 \mathrm{~kg} /$ minute to a maximum of $0.70 \mathrm{~kg} /$ minute.

\section{B. Interface with the Carbothermal Reactor}

The interfaces between the pneumatic regolith feed system and the Carbothermal Reactor are summarized in Table 1 below. The interfaces between two systems were trouble-free in the field: Integration consisted of positioning the pneumatic regolith feed system's output funnel over the Carbothermal Reactor's input hopper, and then attaching the Carbothermal Reactor's command signal cable to the corresponding connector on the pneumatic regolith feed system. Within minutes, the Orbitec team had top-level control of the pneumatic regolith feed system and was sending startup and shutdown commands from within their control software. 
Table 1. Summary of interfaces between the Pneumatic Feed System and the Carbothermal Reactor.

\begin{tabular}{|l|l|}
\hline \multicolumn{1}{|c|}{ Interface Description } & \multicolumn{1}{c|}{ Specification } \\
\hline Physical Interface - Height of Output Funnel & 58 inches, verified in the field at time of test \\
\hline $\begin{array}{l}\text { Physical Interface - Command Signal Cable } \\
\text { Connector }\end{array}$ & $\begin{array}{l}\text { MIL-C-26482 box mount connector, 24V on pin A; } \\
\text { reference voltage on pin B. }\end{array}$ \\
\hline Data Interface - Command Signal Cable Signal & $\begin{array}{l}\text { 24V signal initiates startup, loss of signal initiates } \\
\text { shutdown. }\end{array}$ \\
\hline
\end{tabular}

\section{Interface with the Excavation Rover}

During the field demonstration, the pneumatic regolith feed system accepted delivery of approximately $15-20 \mathrm{~kg}$ of tephra from an excavation rover (Figure 5). The excavation rover scooped up approximately $20 \mathrm{~kg}$ of sieved tephra from a prepared excavation zone, and then delivered most of that load to the hopper. The excavation rover gently collided with the pneumatic regolith feed system while approaching the hopper, and spilled a significant quantity of tephra on the hopper's sealing surfaces while dumping its bucket.

Improved rover control would provide some defense against mishaps of this sort, but mitigation measures can also be incorporated into the pneumatic regolith feed system itself. Attaching navigation aids to the hopper could help to prevent collisions and improve alignment. Likewise, the sealing surface and its surrounding areas may be designed to shed spilled regolith without fouling.
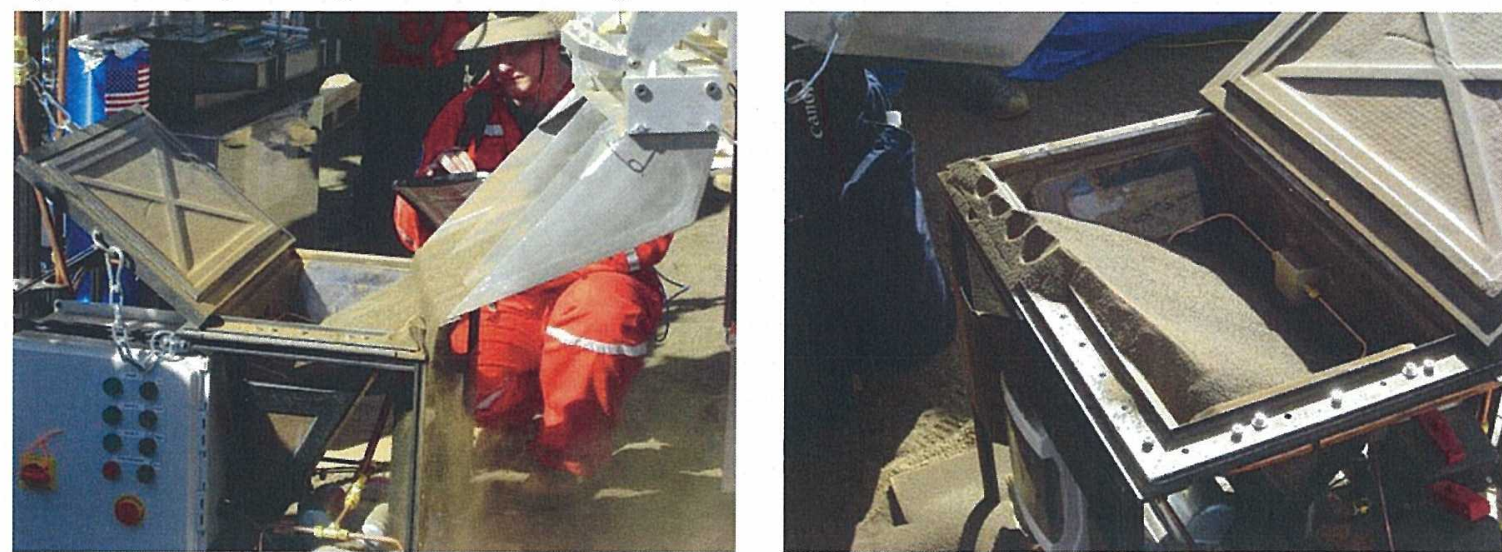

Figure 5. (Left) Accepting tephra from the excavation rover. Note the misalignment of the bucket and hopper. (Right) Heaped tephra on the sealing surface. This must be cleaned off before the lid is capable of sealing.

\section{Filtration}

The lifted regolith is separated from the gas flow by a series of two cyclones, and a HEPA filter then removes any remaining fines from the flow before it cycles back through the compressor (Figure 6). Examination of the HEPA filter during acceptance testing indicated that the filter was removing all fines from the flow, and providing clean air to the compressor. Examination of the hardware during and after field testing indicates that fines were making their way through or around the HEPA filter and through the compressor. This suggests that either: (a) the 5 micron HEPA filter is sufficient to catch all of the fines in the tephra used for acceptance and validation testing, but not sufficient to capture the fines present at the field site, or (b) the HEPA filter was incorrectly installed in the field, creating a leak path around it.

Establishing a good seal around the HEPA filter is an immediate concern. Developing a low-maintenance filtration system is a good area for future concentration. If the HEPA filter does not deliver a flow of clean air to the compressor, then the life of the compressor may be adversely affected. However, the HEPA filter still requires maintenance and replacement on a regular basis. Even if the cyclones operate at an admirable $99.7 \%$ efficiency, fines will accumulate in the filter at a rate of $10 \mathrm{~kg}$ per metric ton of regolith transferred, which is a suitable scale for 
activities such as oxygen production. ${ }^{11} \mathrm{~A}$ more flight-like system will presumably require a longer maintenance interval.
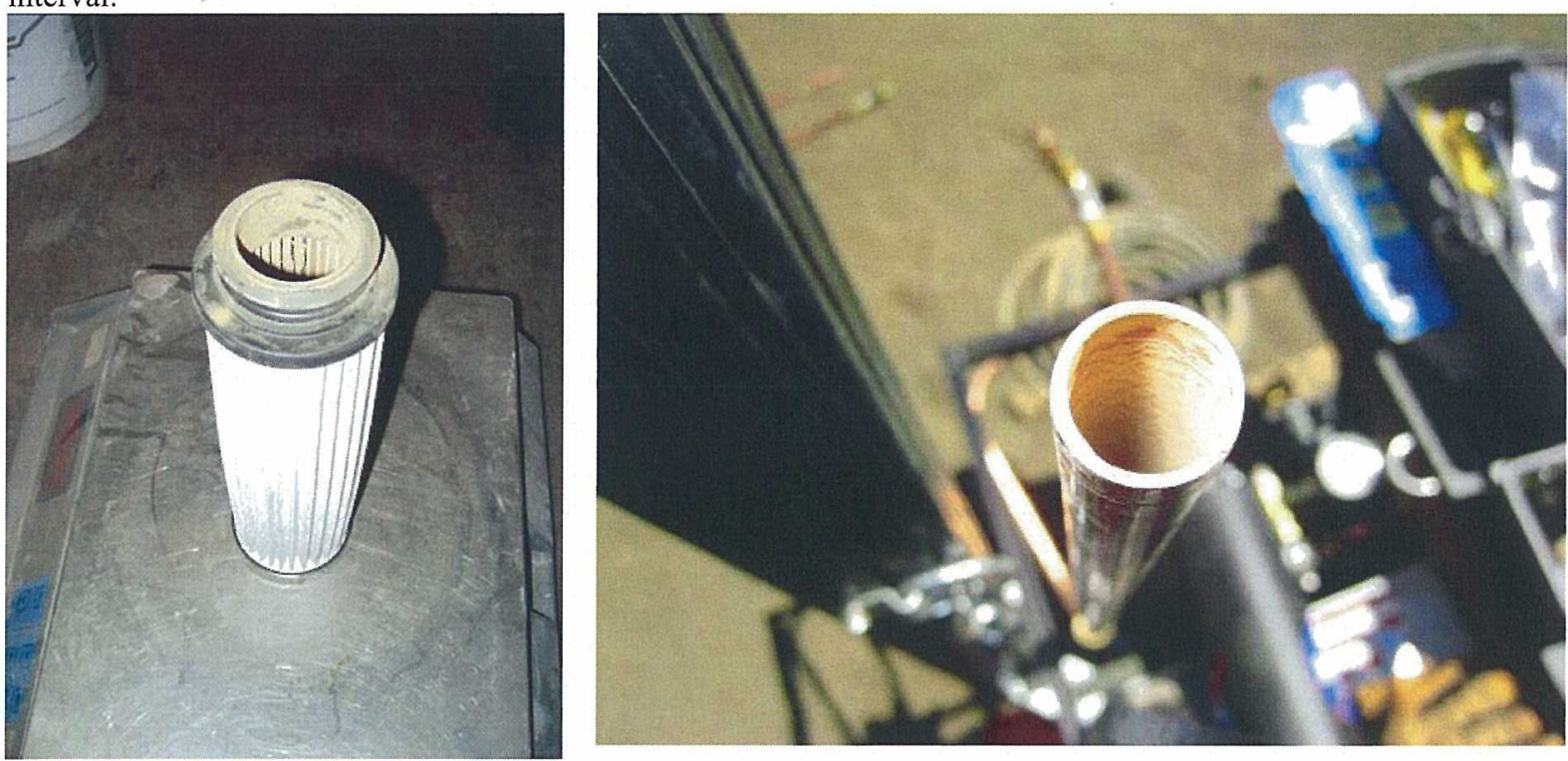

Figure 6. (Left) HEPA filter after acceptance testing. Note the clean outer surface. (Right) Filter outlet pipe during field testing. Note the presence of fine dust on the inside of the pipe.

\section{Appendix - Tephra Transfer Rate Data \\ Tephra Transfer Rate (All Test Data)}

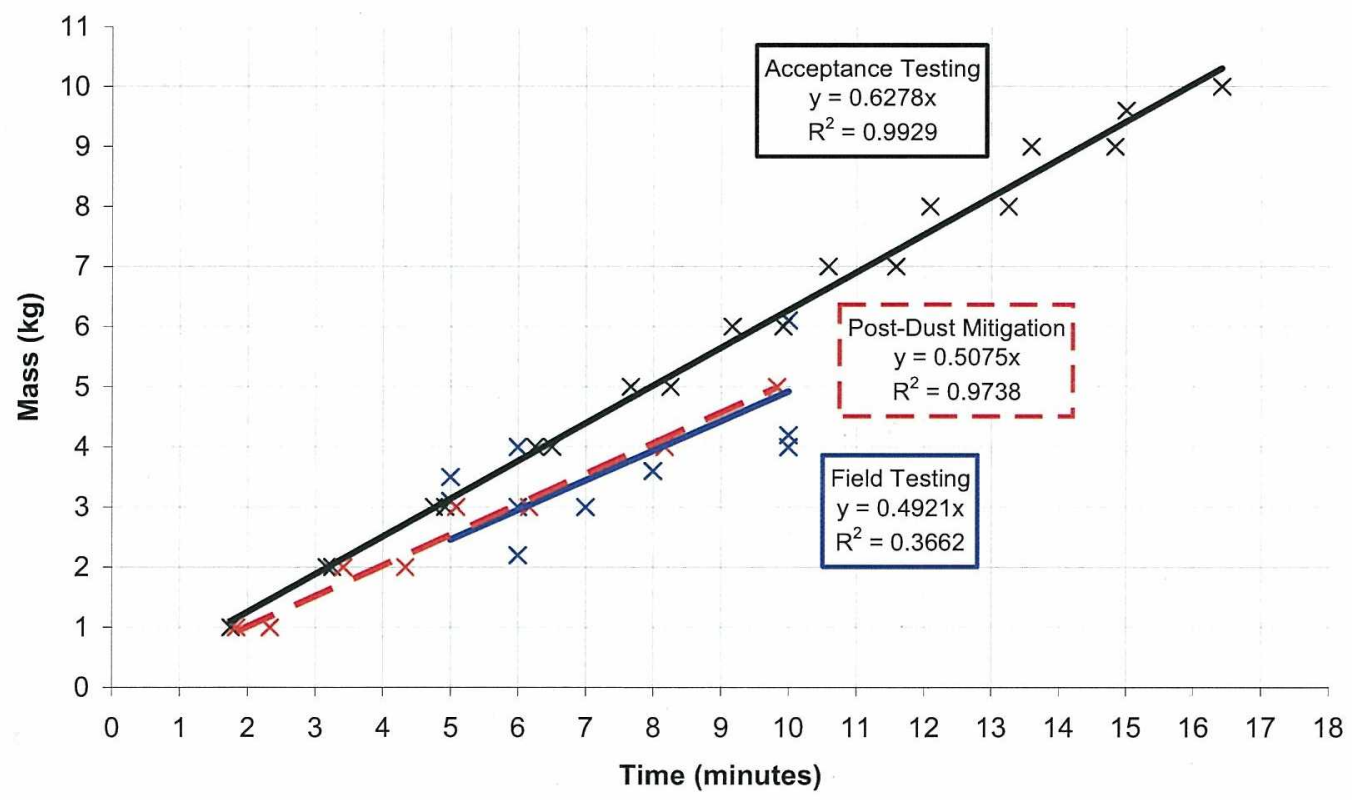

Figure 7. All tephra transfer data recorded, with trendlines. Field testing approximated the post-dust mitigation results, but was more varied than any data recorded in the lab.

\footnotetext{
${ }^{11}$ Mueller \& King, "Trade Study of Excavation Tools and Equipment for Lunar Outpost Development and ISRU, Space Technology and Applications International Forum - STAIF 2008, 2008
}

6 


\section{Tephra Transfer Rate (Acceptance Testing)}

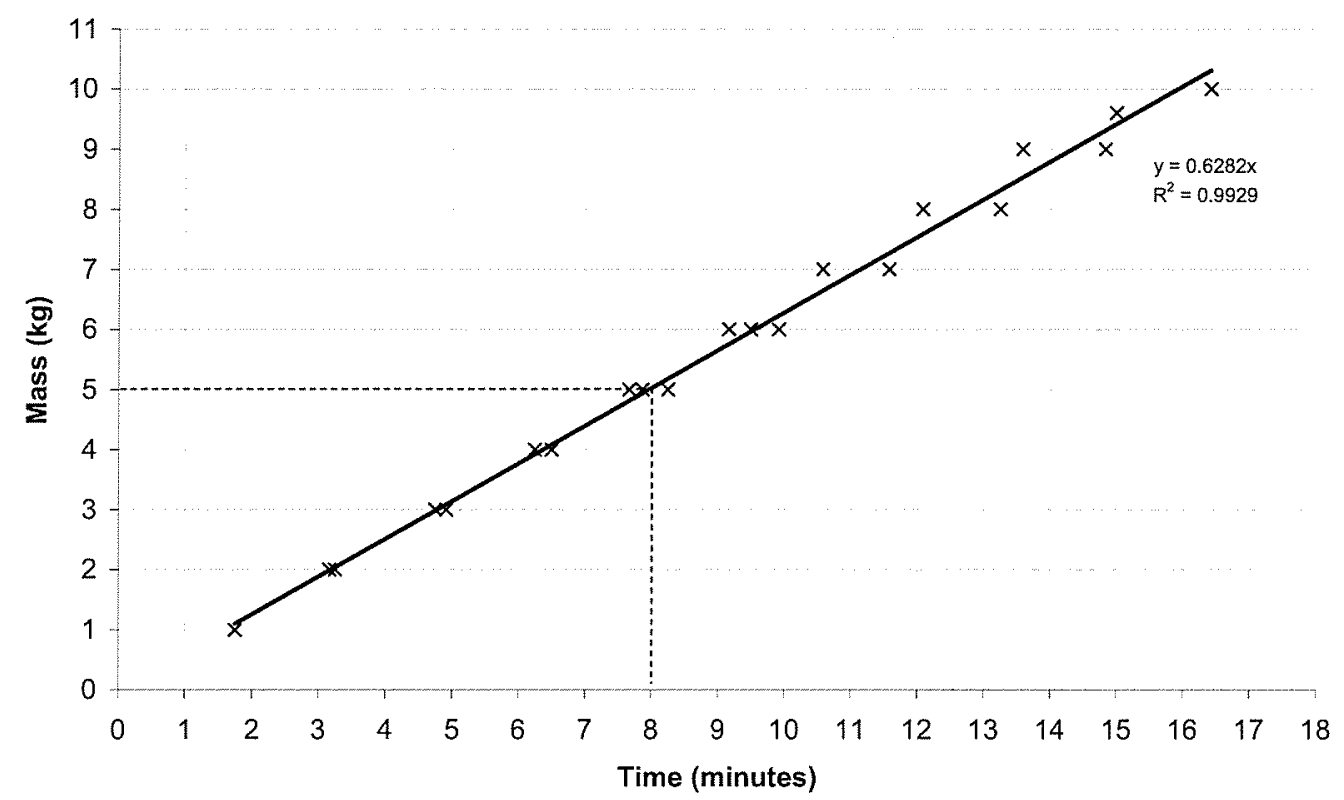

Figure 8. Acceptance testing tephra transfer times, with trendline.

Tephra Transfer Rate (Post-Dust Mitigation Testing)

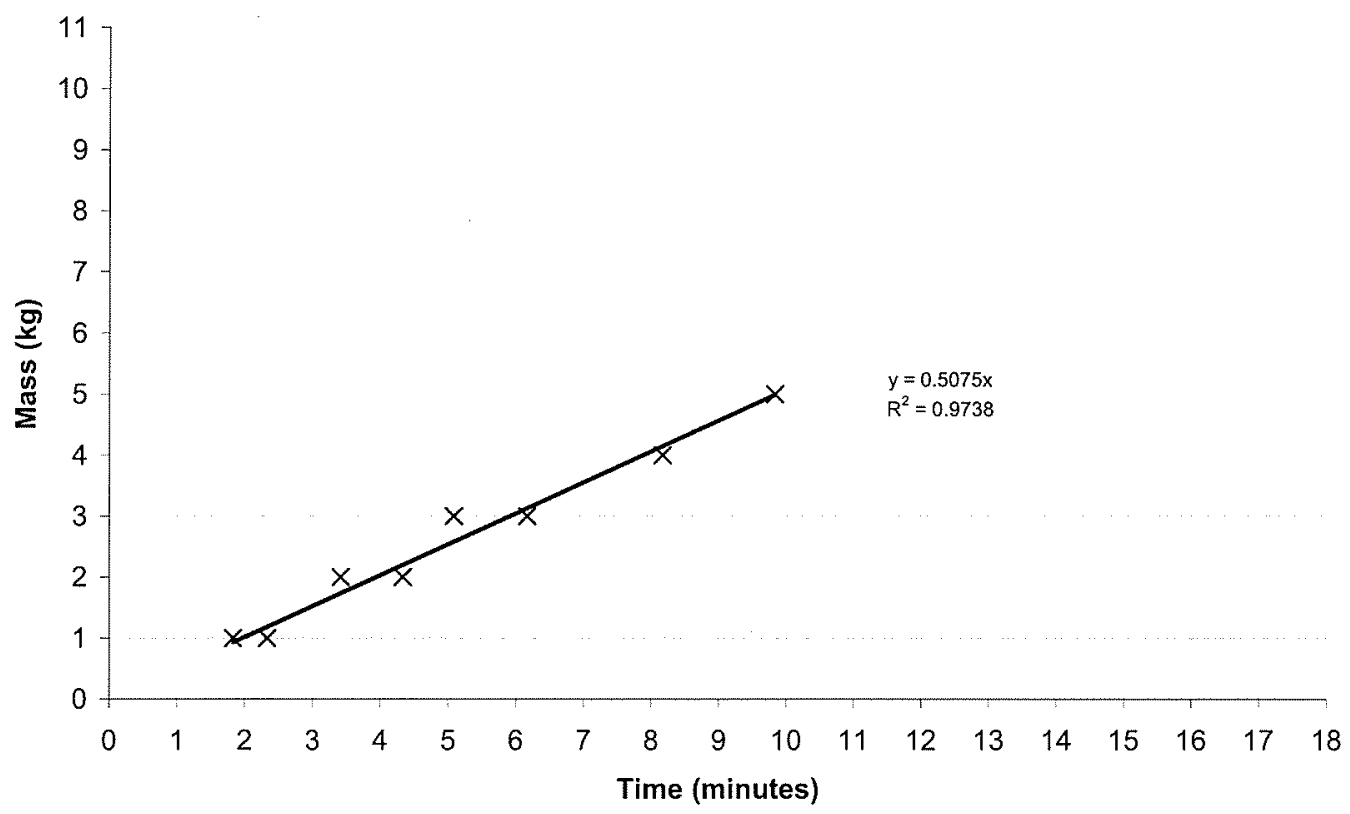

Figure 9. Post-dust mitigation testing tephra transfer times, with trendline. 


\section{Tephra Transfer Rate (Field Testing)}

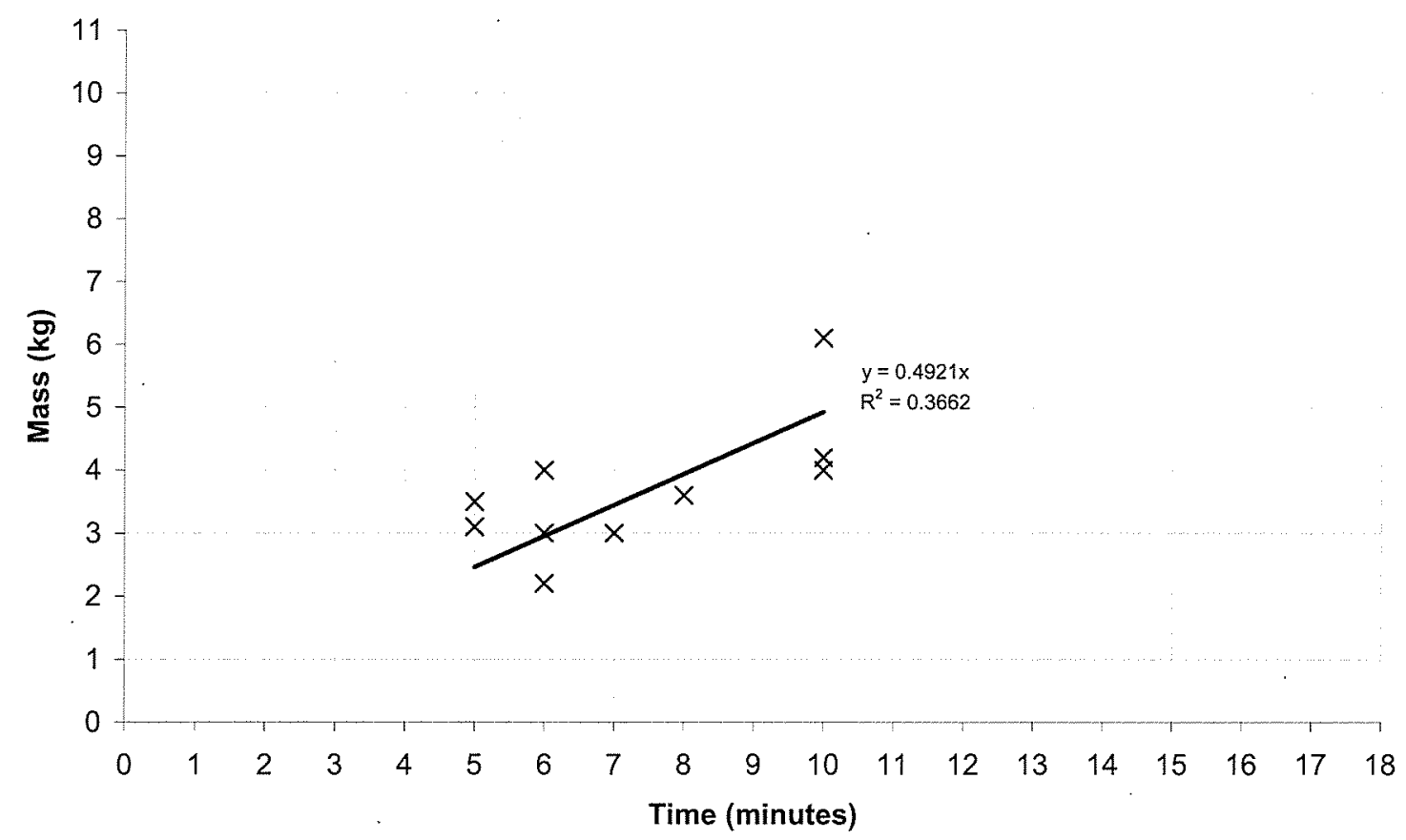

Figure 10. Field testing tephra transfer times, with trendline.

\section{Conclusions}

In this paper, we reported on the design and field demonstration of a pneumatic regolith feed system. The goal of the pneumatic feed system was to move Mauna Kea tephra from a main hopper at ground level to a Carbothermal reactor hopper, $1.6 \mathrm{~m}$ above the ground. The key elements of a closed-loop system were demonstrated under field conditions, and the hardware successfully interfaced to the Carbothermal Reactor.

Lessons learned include the following: 1) it would be desirable for the automatic exclusion of oversized particles, 2) low-maintenance filtration after the cyclones should be investigated, 3) navigation aids or other means of ensuring proper rover alignment to the hopper should be integrated with the system, and 4) sealing surfaces that are capable of shedding large quantities of spilled regolith should be implemented.

\section{Acknowledgments}

This material is based upon work supported by the NASA/Kennedy Space Center, Contract No. NNK09EA87P. This effort leverages previous work performed by both NASA/KSC and Honeybee Robotics. It was performed as an SBIR Phase 3 effort using Innovative Partnership Program (IPP) funds with cost-sharing from Honeybee. The authors thank NASA/KSC and Honeybee Robotics for their support. The authors thank the Pacific International Space Center for Exploration Systems (PISCES), NASA, and the Canadian Space Agency (CSA) for making this field demonstration possible.

\section{References}

1 Caruso, J.J., Greer, Lawrence C.; John, Wentworth T.; Spina, Dan C.; Krasowski, Mike J.; Abel, Phillip B.; Prokop, Norman F.; Flatico, Joseph M.; Sacksteder, Kurt R.,"Cratos: A Simple Low Power Excavation and Hauling System for Lunar Oxygen Production and General Excavation Tasks," PTMSS Conference, Sudbury, Ontario, Canada, 10-13 Jun. 2007

2 Cooke, D. et al, Exploration Strategy and Architecture, Implementing the Vision, 2nd Space Exploration Conference, AIAA, Houston (2006). 
3 Sanders, G.; Larson, W., "NASA In-Situ Resource Utilization (ISRU) Development \& Field Testing," Presentation to " Hawaii's Aerospace Industry: The Next Frontier", Honolulu, The Hawaii State Capital Auditorium, August 21, 2008

4 Schrunk, David G., Sharpe, B.L., Cooper, B.L., and Thangavelu, M. (1999). "The Moon: Resources, Future Development and Colonization," Wiley-Praxis, New York.

5 Mills, David, Jones, M.G., and Agarwal, V.K. (2004). "Handbook of Pneumatic Conveying Engineering."

Marcel-Decker, New York.

6 K. Zacny, G. Mungas, C. Mungas, D. Fisher, and M. Hedlund, Pneumatic Excavator and Regolith Transport System for Lunar ISRU and Construction, Paper No: AIAA-2008-7824 and Presentation, AIAA SPACE 2008 Conference \& Exposition, 9 11 Sep 2008, San Diego Convention Center, San Diego, California

7 Sullivan, Thomas A., Koenig, E., Knudsen, C.W., and Gibson, M.A. (1994). "Pneumatic Conveying of Materials at Partial Gravity," J. Aerosp. Eng. 7(2), 199-208.

8 Ivan Townsend, Robert P. Mueller, James Mantovani, Kris Zacny, Jack Craft, Performance of a Pneumatic Regolith Feed System for and In Situ Resource Utilization Production Plant in a Mauna Kea, Hawaii Analog Field Test, Aerospace Mechanisms Symposium, Orlando, FL, May 12-14, 2010 